\title{
Remoção dos compostos odoríferos geosmina e 2-metilisoborneol de águas de abastecimento através de processos de aeração em cascata, dessorção por ar e nanofiltração
}

Removal of the odoriferous compounds geosmin and 2-methylisoborneol from drinking water by the processes of cascade aeration, air stripping and nanofiltration

\author{
Michely Zat \\ Mestre em Recursos Hídricos e Saneamento Ambiental pelo Instituto de Pesquisas Hidráulicas da Universidade Federal do Rio Grande do Sul (UFRGS)
}

Antonio D. Benetti

Doutor em Engenharia Ambiental por Cornell University, EUA. Professor Associado do Instituto de Pesquisas Hidráulicas da UFRGS

\section{Resumo}

Atividades humanas aceleram o processo natural de eutrofização das águas, favorecendo a floração de algas e cianobactérias. Estes organismos emitem os compostos 2-metilisoborneol (MIB) e geosmina, que conferem gosto e odor de mofo e terra à água. A presença destes compostos se estende à água potável uma vez que os processos convencionais de tratamento são insuficientes para removê-los. Esta pesquisa foi realizada com o objetivo de avaliar alternativas de processos de tratamento para a remoção de MIB e geosmina da água. Os processos estudados foram aeração em cascata, dessorção por ar e nanofiltração. Os resultados sugerem a possibilidade de remoção quase total de MIB e geosmina da água através do sistema de nanofiltração, enquanto que os processos baseados em aeração e dessorção foram relativamente ineficientes.

Palavras-chave: gosto e odor, aeração em cascata, dessorção por ar, nanofiltração, 2-metilisoborneol, geosmina.

\section{Abstract}

Human activities accelerate the natural process of eutrophication, favouring the occurrence of algae and cyanobacterial blooms. These organisms emit the compounds 2-methylisoborneol (MIB) and geosmin, which confer earthy and moldy taste and odor to water. The presence of MIB and geosmin is extended to drinking water inasmuch they are not completely removed by the processes used in conventional treatment. This research was conducted to evaluate the capability of alternative treatment processes to remove MIB and geosmin from water. The processes studied were cascade aeration, air stripping, and nanofiltration. The results suggested that MIB and geosmin can be almost completely removed by nanofiltration, while the processes based on aeration and stripping were relatively inefficient.

Keywords: taste and odor, cascade aeration, air stripping, nanofiltration, 2-methylisoborneol, geosmin. 


\section{Introdução}

As atividades humanas têm contribuído para o comprometimento de grande parte dos ecossistemas aquáticos do Brasil (REBOUÇAS; BRAGA; TUNDISI, 2006) e do mundo (UNEP GEMS, 2008). Um dos principais impactos é a eutrofização das águas, estimulada pelos aportes de nitrogênio e fósforo trazidos por fontes pontuais e difusas de poluição (TUNDISI; TUNDISI, 2008). Ambientes eutrofizados favorecem eventos de florações de algas e cianobactérias, as quais produzem, entre outros, os compostos odoríferos 2-metilisoborneol (MIB) e trans-1,10-dimetil-trans-9-decalol (geosmina). Estes compostos conferem gosto e odor de terra e mofo à água, sendo detectados a concentrações bastante baixas, da ordem de 10 ng. L-1 $^{-1}$ (YOUNG et al., 1996). Eventualmente, a água potável distribuída apresenta gosto e odor ofensivos devido à presença de MIB e geosmina, uma vez que estes compostos são pouco removidos pelos processos convencionais de tratamento (HOEHN; MALLEAVIALLE, 1995; SRINIVASAN; SORIAL, 2011). Por exemplo, nos primeiros meses do ano de 2004 , o lago Guaíba, em Porto Alegre, experimentou uma floração intensa da cianobactéria Planktothrix mougeotii. As concentrações de MIB nas águas bruta e potável chegaram a 1.985 ng.L-1 e 838 ng.L.-1 , respectivamente (BENDATI et al., 2005). Nesta ocasião, a água distribuída apresentava gosto e odor fortes, dando origem a inúmeras reclamações por parte dos consumidores.

Em geral, os consumidores avaliam a qualidade da água potável através das percepções sensoriais de gosto, odor e cor (DORIA, 2010). Uma água segura do ponto de vista químico e microbiológico será reprovada pelos consumidores se sua aparência for desagradável, estimulando o consumo de fontes alternativas, como água engarrafada (McGUIRRE, 1995), ou não seguras do ponto de vista sanitário (THOMPSON et al., 2007).

Os órgãos reguladores da qualidade da água potável consideram gosto e odor como um problema estético, não afetando diretamente a saúde. Isto se reflete nos padrões de potabilidade estabelecidos por diversos países. No Brasil, gosto e odor enquadram-se na categoria de padrões de aceitação, sendo seu valor máximo permitido descrito pela expressão "não objetável" (BRASIL, 2004). Alguns autores argumentam que gosto e odor têm um efeito indireto sobre a saúde. Por exemplo, Jardine, Gibson e Hrudey (1999) afirmam que água de gosto desagradável pode causar efeitos psicossomáticos, como dores de cabeça, estresse e náusea, afetando particularmente aos grupos mais vulneráveis da população.

Os métodos mais usados para remoção de MIB e geosmina são adsorção e oxidação (JUNG; BAEK; YU, 2004). Especialmente em águas de abastecimento com problemas sazonais de gosto e odor, carvão ativado pulverizado (CAP) é o método preferido por sua flexibilidade. Marchetto e Ferreira Filho (2005) concluíram que a aplicação de CAP, antes ou depois do coagulante, não afeta a eficiência da adsorção. Contudo, recomendam a aplicação antes do coagulante de modo a permitir que as partículas de carvão sejam incorporadas aos flocos que serão removidos no decantador. Trabalhando com água destilada artificialmente contaminada com MIB e geosmina, Juliano (2010) obteve remoções superiores a 96\% para ambos contaminantes, usando carvão de coco e dosagem de $30 \mathrm{mg} . \mathrm{L}^{-1}$. Contudo, sabe-se que a presença de matéria orgânica natural diminui a capacidade de adsorção pela competição com os sítios livres do carvão. Em testes com quatro diferentes tipos de águas, Cook, Newcomb e Sztajnbok (2001) observaram maior adsorção de geosmina em comparação a MIB em todos os ensaios. Os autores atribuíram o fenômeno à menor solubilidade e maior peso molecular da geosmina. Drikas, Dixon e Morran (2009) observaram concentrações não detectáveis de MIB e geosmina em ensaios usando cinco filtros de carvão ativado granular (CAG), para concentrações afluentes entre 50 e 200 ng.L-1. Isto foi observado mesmo com água bruta contendo concentrações variáveis de matéria orgânica dissolvida.

MIB e geosmina possuem estrutura molecular alifática, caracterizando-se pela dificuldade em serem oxidados. Glaze et al. (1990) estudaram a aplicação de seis oxidantes (cloro, dióxido de cloro, cloroaminas, permanganato de potássio, peróxido de hidrogênio e ozônio) em águas contendo seis diferentes compostos causadores de gosto e odor. Entre os oxidantes, destacou--se o ozônio, que removeu 78 e 89\% de MIB e geosmina, respectivamente, para uma dose de 4 mg. $\mathrm{L}^{-1}$ de ozônio. Da mesma forma, Park et al. (2007) mediram reduções de 82 e $86 \%$ para MIB e geosmina a uma dose de ozônio de 2,0 mg. $\mathrm{L}^{-1}$. Dois tipos de reações ocorrem com ozônio na água: oxidação direta pela molécula de ozônio e oxidação indireta pelo radical livre hidroxila (GRAMITH, 1995). Os radicais livres são oxidantes ainda mais fortes que ozônio (GLAZE et al., 1990). Este aspecto é explorado no uso de processos oxidativos avançados, como, por exemplo, a combinação de ozônio com peróxido de hidrogênio ou radiação UV. Por exemplo, Park et al. (2007) obtiveram remoção total de MIB e geosmina quando peróxido de hidrogênio foi combinado com ozônio na razão $0,30 \mathrm{mg} \mathrm{H}_{2} \mathrm{O}_{2} \cdot \mathrm{mg}^{-1} \mathrm{O}_{3}$, e concentração de $0,30 \mathrm{mg} \cdot \mathrm{L}^{-1} \mathrm{O}_{3}$.

A Organização Mundial da Saúde refere que, além de adsorção e oxidação com ozônio, aeração é um sistema eficiente para remoção de gosto e odor na água (WHO, 2004). A aeração é usada tanto para remoção de gases e substâncias voláteis indesejadas da água como para a incorporação de gases como o oxigênio. A aeração pode ser feita em torres empacotadas, difusores de ar, chafarizes, aeradores superficiais, de cascata, de tabuleiros e de repuxo (RICHTER; AZEVEDO NETTO, 1991; HAND, HOKANSOM; CRITTENDEN 1999). Lalezary et al. (1984) realizaram experimentos com colunas de dessorção por ar visando determinar as constantes de Henry para cinco compostos causadores de gosto e odor na água. Foram medidos os valores 0,0576 e 0,066 atm. $\mathrm{M}^{-1}$, respectivamente para MIB e geosmina. São considerados voláteis compostos com constante de Henry maiores do que 0,1 atm. $\mathrm{M}^{-1}$ (NAZAROFF; ALVAREZ-COHEN, 2001). Os autores observaram, também, que as remoções dos compostos odoríferos 
dependiam de suas concentrações iniciais. As reduções de MIB, para concentrações iniciais de 100 e 10.000 ng. $\mathrm{L}^{-1}$, variaram entre 45 e $75 \%$; as reduções de geosmina, para as mesmas concentrações iniciais, foram de 65 e $80 \%$. Os requerimentos de altas razões ar para água limitam o uso da dessorção por ar para remoção de compostos pouco voláteis da água. Em algumas situações, estas altas razões só podem ser atingidas com reduções nas taxas de aplicação do líquido a valores menores do que aqueles necessários para manter o material de enchimento completamente molhado (MERTOOETOMO et al., 1993). Estes autores introduziram uma modificação em relação aos sistemas convencionais de contato ar-água realizados com fluxos opostos ou paralelos. No sistema proposto, o fluxo de ar atravessa o líquido transversalmente, tantas vezes quanto for o número de estágios, possibilitando um aumento na razão ar:água. Em experimentos realizados neste sistema, os autores mediram remoções superiores àquelas verificadas em sistemas convencionais de contra-corrente, possibilitando a dessorção de compostos pouco voláteis.

A técnica de separação em membranas vem tendo uso crescente para a remoção de microrganismos patogênicos e compostos dissolvidos na água (JEFFERSON, GRAY; DIXON, 2007). MIB e geosmina possuem pesos moleculares de 168 e $182 \mathrm{Da}$, respectivamente (REISS et al., 2006). Assim, membranas de microfiltração (MF) e ultrafiltração (UF) pouco retêm estes compostos considerando que seus pesos moleculares de corte são superiores a $500 \mathrm{Da}$. Contudo, a associação de CAP com membrana de UF foi capaz de reduzir o NLO (Número Limiar de Odor) de 9 para 2, em testes referidos por Bruchet e Lainé (2005). Dixon et al. (2011) investigaram as remoções de microcistina, MIB e geosmina em quatro membranas comerciais de nanofiltração, com pesos moleculares de corte entre 100 e 600 Da. Os testes foram feitos em dois tipos de águas contendo diferentes concentrações de carbono orgânico dissolvido. Remoções superiores a 80 e 95\% foram atingidas para geosmina e MIB, respectivamente, pela membrana de $100 \mathrm{Da}$, em ambos os tipos de água. A membrana de maior porosidade (600-800 Da) apresentou remoções inferiores a 40\%.

Testes realizados por Reiss et al. (2006) com membranas de MF e UF mostraram reduções da ordem de 20 a 30\% para MIB e 30 a 40\% para geosmina. Em ensaios com membranas de nanofiltração, foram obtidas reduções superiores a 99\% para ambos os compostos, com membrana de poliamida e $200 \mathrm{Da}$ de corte. Em membrana de acetato de celulose, com peso molecular de corte de $300 \mathrm{Da}$, as reduções atingiram 37 e 58\% para MIB e geosmina, respectivamente. Nestes ensaios, as concentrações dos compostos eram da ordem de 100 ng. $\mathrm{L}^{-1}$.

O trabalho descrito neste artigo teve o propósito de avaliar a eficiência de sistemas de aeração e separação em membranas na remoção de MIB e geosmina de água de abastecimento. Os processos estudados foram aeração em cascata, dessorção por ar e nanofiltração, utilizando, como fonte de abastecimento, um manancial de água com histórico de florações de algas e cianobactérias. Há relativamente poucos estudos com relação à eficiência destes processos na remoção de MIB e geosmina.

\section{Metodologia}

Para a realização dos experimentos, foram projetados e construídos protótipos de aeração em cascata, torre de dessorção por ar e separação em membranas de nanofiltração. Os protótipos foram instalados na Estação de Tratamento de Água Lomba do Sabão, de propriedade do Departamento Municipal de Água e Esgotos (DMAE) de Porto Alegre (RS), Brasil.

\section{Água de abastecimento aos protótipos}

O reservatório Lomba do Sabão fornece 3,6\% da água captada para abastecimento público da cidade de Porto Alegre. Apresenta área de drenagem de 1.428 ha e volume médio de 3 milhões de $\mathrm{m}^{3}$. Em épocas de verão têm sido observadas florações de algas e cianobactérias e o aparecimento de gosto e odor na água potável (MAIZONAVE et al., 1999). Entretanto, no período de realização dos experimentos, o reservatório apresentava uma cobertura de macrófitas, cujo sombreamento da água impedia o desenvolvimento de florações. Deste modo, as concentrações de MIB e geosmina na água do reservatório permaneceram baixas, sendo necessário contaminar a água afluente aos protótipos com MIB e geosmina.

\section{Fluxo da água aos protótipos}

Para realização dos experimentos, a água bruta da represa era recalcada para um reservatório de polietileno de 2.500 L. Antes de ingressar neste reservatório, a água passava por um filtro de piscina marca DANCOR ${ }^{\circledR}$ modelo DFR-12, com meio filtrante de areia e área de filtração de $0,07 \mathrm{~m}^{2}$. Havia ainda um filtro tipo Y, DN32 com perfuração do elemento filtrante de $0,8 \mathrm{~mm}$.

Depois de ser contaminada no reservatório com MIB e geosmina (1.200 ng. L L $^{-1}$ cada, Wako Chemicals Inc.), a água era bombeada para os três protótipos, sendo os efluentes conduzidos a tanques de armazenagem. Nestes tanques eram coletadas as amostras para análises. A Figura 1 apresenta o fluxograma de funcionamento dos protótipos.

\section{Protótipos}

\section{a) Aerador tipo cascata}

O protótipo do aerador tipo cascata foi construído com quatro plataformas de acrílico, circulares, com diâmetros entre 0,20 e 1,20 m e sobrepostas em 0,25 m. O aerador operou com taxas de aplicação superficial de $5,1 \mathrm{~m}^{3} \cdot \mathrm{m}^{-2} \cdot \mathrm{d}^{-1}, 7,7 \mathrm{~m}^{3} \cdot \mathrm{m}^{-2} \cdot \mathrm{d}^{-1}$ e $10,2 \mathrm{~m}^{3} \cdot \mathrm{m}^{-2} \cdot \mathrm{d}^{-1}$. Os testes foram realizados em batelada, com tempos de duração média de 125, 83 e 63 min, para as respectivas taxas de aplicação. Além do aerador, o sistema era formado por bomba centrífuga, rotâmetro, tanque de armazenamento do efluente (1.000 L), tubulações, válvulas, conexões e acessórios. Foram realizadas 10 repetições para cada taxa de aplicação utilizada. 


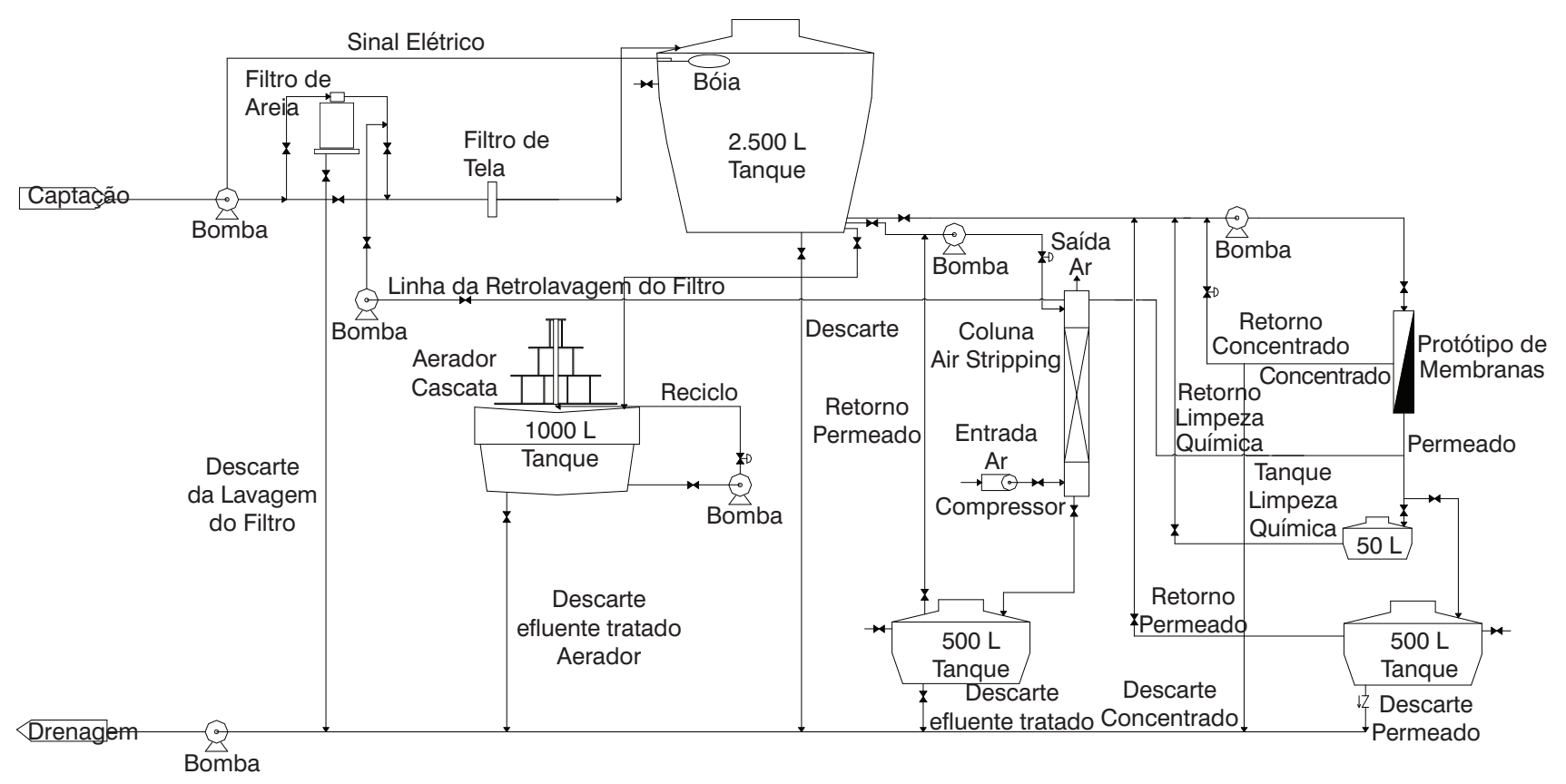

Figura 1 - Fluxograma de funcionamento dos protótipos.

\section{b) Coluna de dessorção por ar}

A coluna de dessorção por ar, fabricada em acrílico, tinha diâmetro de $20 \mathrm{~cm}$ e altura de 1,83 m. A coluna foi preenchida com anéis Pall Rings de polietileno e tamanho 5/8". Continha duas plataformas, superior e inferior, para distribuição dos fluxos de água e ar. A plataforma inferior tinha, também, a função de sustentar o material de enchimento.

A coluna foi operada em batelada a taxas de fluxo do líquido de 4 L.min' ${ }^{-1}, 6$ L.min ${ }^{-1}$ e 8 L.min ${ }^{-1}$, vazão de ar de 0,8 L.s ${ }^{-1}$ e razão ar/água de 6,8 e $12 \mathrm{~m}^{3} \cdot \mathrm{m}^{-3}$. A água contaminada com MIB e geosmina entrava na parte superior da coluna através de um distribuidor tipo chuveiro. A corrente de ar era injetada em contra-corrente à direção da água contaminada através de um compressor, marca Motomil. O material inerte de preenchimento favorece o aumento do contato ar-água, propiciando a passagem do contaminante da fase líquida para a gasosa de modo a se estabelecer o equilíbrio previsto pela Lei de Henry (NAZAROFF; ALVAREZ-COHEN, 2001).

Após a passagem pela coluna o efluente era direcionado para um tanque de armazenamento de $500 \mathrm{~L}$, onde as amostras foram coletadas. O ar injetado na coluna saía para a atmosfera por um orifício aberto no topo do protótipo. Foram realizadas 10 repetições para cada razão ar:água estudada. A duração média de cada experimento variou de 32 a $63 \mathrm{~min}$

\section{c) Membrana de nanofiltração}

O sistema de nanofiltração utilizou membrana em espiral de poliamida, marca Osmonics, modelo DK4040F, armazenada em vazo de pressão. A membrana possuía área efetiva de $8,36 \mathrm{~m}^{2}$ e peso molecular de corte de 150-300 Da (INVICT, 2008). A pressão típica de operação situou-se entre 810 a $900 \mathrm{kPa}$, com taxa de fluxo de água de 4 L.min-1. O sistema de nanofiltração era constituído, ainda, por bomba centrífuga multi-estágio, manômetros de pressão e medidor de vazão, além de tubulações, válvulas e conexões. Foram realizados 10 ensaios, cada qual com duração de 125 minutos. Os ensaios foram conduzidos sem recirculação do concentrado, sendo o permeado coletado em tanque de armazenamento de $500 \mathrm{~L}$.

\section{d) Metodologias analíticas e preservação das amostras}

As análises para determinação dos compostos MIB e geosmina foram realizadas em cromatógrafo a gás acoplado a espectrômetro de massas (GCMS, marca Varian 3800 Saturn 2000). MIB e geosmina eram extraídos das amostras de água afluente e efluente através da técnica de microextração em fase sólida (SPME), sendo, em seguida, identificadas e quantificadas no GCMS (LLOYD et al., 1998). As amostras eram acondicionadas em frascos vials de $30 \mathrm{~mL}$ e mantidas refrigeradas antes de serem processadas. Os ensaios nos protótipos foram realizados entre os meses de julho a agosto de 2008. As temperaturas da água no período variaram entre 16 e $20^{\circ} \mathrm{C}$. 


\section{Resultados}

\section{Remoção de MIB e geosmina no aerador em cascata}

A Tabela 1 mostra as concentrações de MIB e geosmina presentes nos afluentes e efluentes do sistema de aeração em cascata e as respectivas remoções para as diferentes variáveis operacionais testadas. Na Figura 2, são apresentados os valores de MIB medidos em gráficos Box, mostrando valores mínimos e máximos, mediana, primeiro e terceiro quartis. O gráfico de geosmina (não mostrado) apresenta o mesmo padrão da Figura 2.

\section{Remoção de MIB e geosmina na torre de dessorção por ar}

$\mathrm{Na}$ Tabela 2, são apresentados os valores das concentrações de MIB e geosmina presentes nos afluentes e efluentes da coluna de dessorção, para as diferentes razões ar:água. A Figura 3 mostra as concentrações de geosmina em gráfico Box. O gráfico para MIB (não apresentado) tem padrão semelhante ao de geosmina.

\section{Remoção de MIB e geosmina no sistema de nanofiltração}

A Tabela 3 apresenta as concentrações de MIB e geosmina presentes nos afluentes e efluentes do sistema de nanofiltração. Na Figura 4 são apresentadas as concentrações de MIB e geosmina em gráfico Box.

\section{Discussão}

As remoções médias de MIB no aerador situaram-se entre 25 e $28 \%$, enquanto que as obtidas para geosmina foram um pouco superiores, na faixa entre 29 a 34\%. Na coluna de dessorção por ar, as remoções médias foram mais baixas e tiveram maior amplitude, respectivamente, 10 a 24\% para MIB e 17 a 35\% para geosmina. Embora aeração seja uma técnica de tratamento comum para remoção de gosto e odor, sua eficiência está associada ao tipo de substância odorífera presente na água (LOGSDON; HESS; HORSLEY, 1999). As remoções relativamente baixas observadas devem estar associadas ao fato de MIB e geosmina serem compostos semivoláteis, com constantes de Henry da ordem de $10^{-2}$ atm.M ${ }^{-1}$ (LALEZARY et al.,1984; WESTERHOFF et al., 2005). Compostos voláteis apresentam constantes de Henry superiores a $10^{-1} \mathrm{~atm}^{-1}$ (NAZAROFF; ALVAREZ-COHEN, 2001). Trabalhando com colunas de dessorção por ar, Mertooetomo et al. (1993) obtiveram reduções próximas a 70\% para compostos semivoláteis com constantes de Henry de mesma ordem de magnitude que MIB e geosmina. Todavia, as razões ar:água utilizadas eram superiores a seis vezes àquelas utilizadas nos ensaios aqui descritos. Isto sugere que remoções superiores às medidas nos ensaios realizados poderiam ser obtidas com o aumento da razão ar:água. Contudo, este efeito não foi

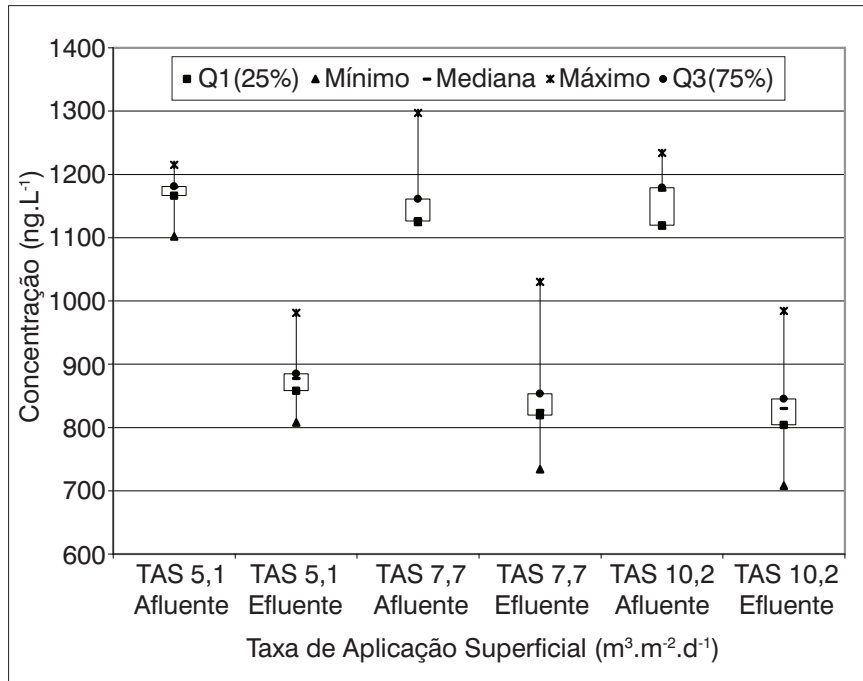

Figura 2 - Variações nas concentrações de MIB no afluente e efluente do aerador em cascata, para as taxas de aplicações superficiais (TAS) avaliadas.

Tabela 2 - Concentrações de MIB e geosmina nos afluentes e efluentes da coluna de dessorção por ar, nas condições de operação testadas (ng. $\mathrm{L}^{-1}$ )

\begin{tabular}{lcccc} 
& \multirow{2}{*}{$\begin{array}{c}\text { Afluente } \\
\text { (reservatório) }\end{array}$} & \multicolumn{3}{c}{ Efluente } \\
\cline { 3 - 5 } & & 6 & 8 & 12 \\
\hline MIB & $1.163 \pm 78$ & $878 \pm 42$ & $984 \pm 102$ & $1.044 \pm 60$ \\
R & & 24 & 15 & 10 \\
Geosmina & $1.153 \pm 73$ & $756 \pm 40$ & $868 \pm 91$ & $958 \pm 71$ \\
R & & 35 & 25 & 17 \\
\hline
\end{tabular}

Concentração média \pm desvio padrão; $R=$ remoção (\%); $n=10$

Tabela 1 - Concentrações de MIB e geosmina nos afluentes e efluentes do sistema de aeração tipo cascata, nas condições de operação testadas (ng. L $^{-1}$ )

\begin{tabular}{|c|c|c|c|c|c|c|}
\hline & \multicolumn{6}{|c|}{ Taxa de Aplicação Superficial $\left(\mathrm{m}^{3} \cdot \mathrm{m}^{-2} \cdot \mathrm{d}^{-1}\right)$} \\
\hline & \multicolumn{2}{|c|}{5,1} & \multicolumn{2}{|c|}{7,7} & \multicolumn{2}{|c|}{10,2} \\
\hline & Afluente & Efluente & Afluente & Efluente & Afluente & Efluente \\
\hline MIB & $1.173 \pm 28$ & $879 \pm 43$ & $1.160 \pm 57$ & $846 \pm 75$ & $1.166 \pm 37$ & $836 \pm 71$ \\
\hline $\mathrm{R}$ & \multicolumn{2}{|c|}{25} & \multicolumn{2}{|c|}{27} & \multicolumn{2}{|c|}{28} \\
\hline Geosmina & $1.091 \pm 33$ & $778 \pm 25$ & $1.104 \pm 62$ & $752 \pm 61$ & $1.092 \pm 42$ & $717 \pm 44$ \\
\hline $\mathrm{R}$ & \multicolumn{2}{|c|}{29} & \multicolumn{2}{|c|}{32} & \multicolumn{2}{|c|}{34} \\
\hline
\end{tabular}

Concentração média \pm desvio padrão; $R=$ remoção $(\%) ; n=10$ 


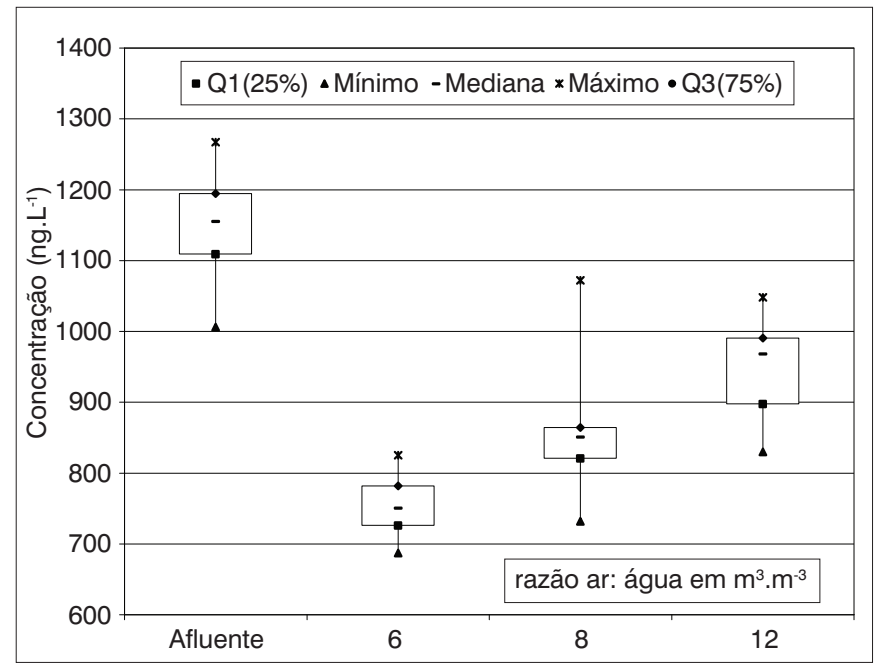

Figura 3 - Variações nas concentrações de geosmina no afluente e efluente da coluna de dessorção por ar, para as razões ar:água avaliadas.

Tabela 3 - Concentrações de MIB e geosmina nos afluentes e efluentes do sistema de nanofiltração (ng. $\left.\mathrm{L}^{-1}\right)$

\begin{tabular}{lccc} 
& Afluente & & Efluente \\
MIB & $1.184 \pm 21$ & & $31 \pm 6$ \\
\hline R & & 97 & \\
Geosmina & $1.144 \pm 29$ & & $49 \pm 9$ \\
\hline R & & 96 & \\
\hline
\end{tabular}

Concentração média \pm desvio padrão; $R=$ remoção $(\%) ; n=10$

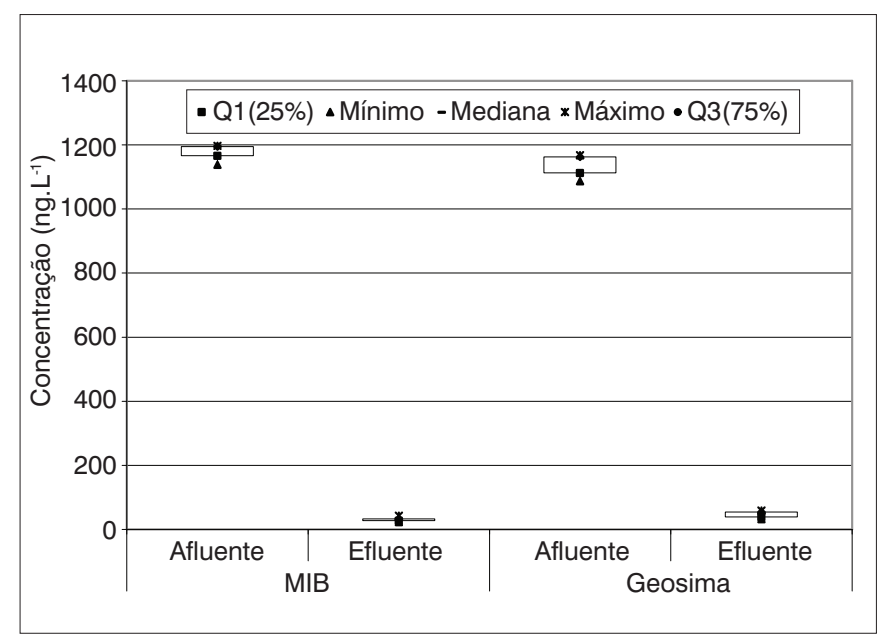

Figura 4 - Variações nas concentrações de MIB e geosmina no afluente e efluente do sistema de nanofiltração.

observado no presente trabalho, onde houve uma redução na eficiência com o aumento da razão ar:água. Uma hipótese para esta observação seria o possível aparecimento de caminhos preferenciais no recheio da torre com o aumento da vazão de água, limitando o contato entre as fases líquida e gasosa. Em estudo com coluna de dessorção, Lalezary et al. (1984) mediram reduções superiores às observadas nesta pesquisa. Para MIB e geosmina, estes autores observaram reduções de 45-75\% e 65-80\%, respectivamente, dependendo das concentrações iniciais dos contaminantes.
Ao contrário da coluna de dessorção, o aumento na taxa de aplicação superficial do aerador tipo cascata melhorou a remoção de MIB e geosmina. É possível que isso tenha ocorrido devido à maior turbulência da água, a qual pode ter contribuído para um maior contato entre as fases, e, consequentemente, uma maior transferência dos compostos voláteis. A turbulência aumenta a área interfacial e a taxa de transferência de massa por unidade de área, pois ajuda a dispersar um fluido no outro (MERTOOETOMO et al., 1993)

Um fato que chamou a atenção durante os ensaios foi o forte cheiro de mofo e terra, característico de MIB e geosmina, que se fazia sentir no local do experimento, tão logo os sistemas de aeração e dessorção entravam em operação. Isto demonstrou que estava havendo volatilização de MIB e geosmina em quantidades que, mesmo pequenas, eram facilmente perceptíveis ao olfato humano. Esta observação vem ao encontro de relatos de pessoas que se sentiram incomodadas com o cheiro da água em banhos com chuveiros durante episódios de presença de MIB e geosmina na água potável distribuída (MAGALHÃES, 2004).

Embora não documentado nesta pesquisa, é possível que ocorra crescimento de biofilme junto à superfície do material inerte de enchimento da coluna de dessorção uma vez que a água de abastecimento possui carbono orgânico capaz de suportar crescimento bacteriano. Também não foi avaliado de que maneira este biofilme afeta o processo de troca gasosa que ocorre na torre de dessorção.

Outro fator que pode ter contribuído para uma redução na eficiência da dessorção foi o fato do ar injetado na coluna ser ar atmosférico proveniente do próprio local dos ensaios. Como os protótipos de dessorção e aeração em cascata operavam simultaneamente, o ar injetado na torre provavelmente continha traços do contaminante, resultando em uma diminuição do gradiente de concentração do contaminante nas fases líquida e gasosa.

Nos ensaios realizados com membrana de nanofiltração, as remoções médias de MIB e geosmina foram bastante altas, respectivamente, 97 e 96\%. Também, observou-se que os resultados foram consistentes, com baixos desvios padrões e amplitudes entre mínimos e máximos.

A membrana utilizada, segundo o fabricante, possui um cut-off entre 150 a $300 \mathrm{Da}$. MIB e geosmina possuem pesos moleculares de 168 e 182 Da, respectivamente. Desta forma, as remoções são compatíveis com o ponto de corte da membrana. Além da retenção física pelo tamanho de poros, as membranas têm capacidade de remover alguns compostos com peso molecular inferior a abertura dos poros através dos mecanismos de formação de bolo junto à superfície da membrana e adsorção junto aos seus poros (WEF, 2006).

Os resultados medidos nestes ensaios confirmam aqueles obtidos por Reiss et al. (2006), que trabalharam com membranas de poliamida análogas a usada no protótipo. Em planta piloto, estes autores mediram reduções superiores a 99\% de MIB e geosmina. 


\section{Conclusões}

Os ensaios realizados demonstraram as limitações existentes para a remoção de MIB e geosmina em sistemas baseados em aeração e trocas gasosas. MIB e geosmina são compostos semivoláteis, sendo as remoções observadas compatíveis com esta característica. Ao contrário, nos testes feitos com o sistema de nanofiltração, as remoções foram bastante altas, superiores a $95 \%$, sugerindo o potencial desta tecnologia para o tratamento de águas de abastecimento sujeitas a episódios de gosto e odor devido a MIB e geosmina.

Todos os ensaios foram feitos em batelada, o que é uma limitação deste estudo. Particularmente no sistema de nanofiltração, há necessidade de operação em fluxo contínuo para se medir parâmetros operacionais como variações de pressão, índices de fouling, volume de rejeitos, rendimento e freqüência de lavagens.

\section{Agradecimentos}

Os autores agradecem à Financiadora de Estudos e Projetos (FINEP) pelo financiamento da pesquisa, ao Conselho Nacional de Desenvolvimento Científico e Tecnológico (CNPq) pela bolsa DTI, e ao Departamento Municipal de Água e Esgotos de Porto Alegre (DMAE) pela disponibilização do espaço para implantação dos protótipos.

\section{Referências}

BENDATI, M.M.; MAIZONAVE, C.R.M.; FACCHIN, J.M.J.; et al. (2005). Ocorrência de floração de cianobactéria Planktothrix mougeotti no Lago Guaíba em 2004: atuação do DMAE no abastecimento público. In: XXIII Congresso Brasileiro de Engenharia Sanitária e Ambiental. Anais. Campo Grande: ABES. 1 CD

BRASIL. Ministério da Saúde. Portaria MS No 518. Estabelece os procedimentos e responsabilidades relativos ao controle e vigilância da qualidade da água para consumo humano e seu padrão de potabilidade, e dá outras providências. Diário Oficial da União, 26 de mar. 2004.

BRUCHET, A.; LAINÉ, J.M. (2005). Efficiency of membrane processes for taste and odor removal. Water Science and Technology, v. 51, n. 6-7, p. $257-265$

COOK, D.; NEWCOMB, G.; SZTAJNBOK, P. (2001). The application of powdered activated carbon for MIB and geosmin removal: predicting PAC doses in four raw waters. Water Research, v. 35, n. 5, p. 1325-1333.

DIXON, M.B.; FALCONET, C.; HO, L.; et al. (2011). Removal of cyanobacterial metabolites by nanofiltration from two treated waters. Journal of Hazardous Materials, v. 188, p. 288-295.

DORIA, M.F. (2010). Factors influencing public perception of drinking water quality. Water Policy, v. 12, n. 1, p. 1-19.

DRIKAS, M.; DIXON, M.; MORRAN, J. (2009). Removal of MIB and geosmin using granular activated carbon with and without MIEX pretreatment. Water Research, v. 43, p. 5151-5159.

GLAZE, W.H.; SCHEP, R.; CHAUNCEY, W.; et al. (1990). Evaluating oxidants for the removal of model taste and odor compounds from a municipal water supply. Journal American Water Works Association, v. 82, n. 5, p. 79-84.

GRAMITH, J.T. (1995). Oxidation processes: ozone. In: SUFFET, I. H.; MALLEVILLE, J.; KAWCZYNSKI, E. (eds.) Advances in Taste-and-Odor Treatment and Control. Denver, CO: American Water Works Association Research Foundation and Lyonnaise des Eaux, cap. 3, p. 123-144.
HAND, D.W.; HOKANSOM, D.R.; CRITTENDEN, J.C. (1999). Air stripping and aeration. In: LETTERMAN, R. D. (Ed.). Water Quality and Treatment: a Handbook of Community Water Supplies. 5th ed. New York: McGraw-Hill/ American Water Works Association, cap. 5, p. 5.1-5-68.

HOEHN, R.; MALLEVIALE, J. (1995). Treatment trains. In: SUFFET, I. H.; MALLEVILLE, J.; KAWCZYNSKI, E. (Eds) Advances in Tasteand-Odor Treatment and Control. Denver, CO: American Water Works Association Research Foundation and Lyonnaise des Eaux, cap. 9 p. 351-385.

INVICT. (2008) Manual de Procedimento de Operação de Membranas D-Series. São Paulo.

JARDINE, C.G.; GIBSON, N.; HRUDEY, S.E. (1999). Detection of odour and health risk perception of drinking water. Water Science and Technology, v. 40, n. 6, p.91-98.

JEFFERSON, B.; GRAY, S.; DIXON, D. (2007). Special issue: membranes. Water Research, v. 41, p. 3793.

JULIANO, V.B. (2010). Remoção dos Compostos 2-Metilisoborneol e Geosmina de Água de Abastecimento por Carvão Ativado Granular e Ação Microbiana. Tese (Doutorado em Recursos Hídricos e Saneamento Ambiental) - Instituto de Pesquisas Hidráulicas, Universidade Federal do Rio Grande do Sul, Porto Alegre.

JUNG, S.-W.; BAEK, K.-H.; YU, M.-J. (2004). Treatment of taste and odor material by oxidation and adsorption. Water Science and Technology, v. 49 , n. 3, p. 289-295.

LALEZARY, S., PIRZABARI, M.; McGUIRE, M.J.; et al. (1984). Air stripping of taste and odor compounds from water. Journal American Water Work Association, v. 76, n. 3, p. 83-87.

LLOYD S.W.; LEA, J.M.; ZIMBA, P.V.; et al. (1998). Rapid analysis of geosmin and 2-methylisoborneol in water using solid phase micro extraction procedures. Water Research, v. 32, n. 7, p. 2140-2146. 
LOGSDON, G.; HESS, A.; HORSLEY, M. (1999). Guide to selection of water treatment processes. In: LETTERMAN, R. D. (ed.). Water Quality and Treatment: a Handbook of Community Water Supplies. 5th ed. New York: McGraw-Hill/American Water Works Association, cap. 3, p. 3.1-3.26.

MAGALHÃES, C. Aumenta descontentamento com gosto da água. Jornal Zero Hora, p. 38, 16 mar. 2004. Porto Alegre.

MAIZONAVE, C.R.M.; MORANDI, I.C.; JUNQUEIRA, I.C.; et al. (1999). Reservatório da Lomba do Sabão: Qualidade da Água e Problemas Operacionais no Tratamento. Porto Alegre: Departamento Municipal de Água e Esgotos, $21 \mathrm{p}$.

MARCHETTO, M.; FERREIRA FILHO, S.S. (2005). Interferência do processo de coagulação na remoção de compostos orgânicos causadores de gosto e odor em águas de abastecimento mediante a aplicação de carvão ativado em pó. Revista Engenharia Sanitária e Ambiental, v. 10, n. 3, p. 243-252.

McGUIRRE, M. (1995). Off-flavor as the consumer's measure of drinking water safety. Water Science and Technology, v. 31, n. 11, p. 1-8.

MERTOOETOMO E.; VALSARAJ, K.T.; WETZEL, D.M.; et al. (1993). Cascade crossflow air stripping of moderately volatile compounds using high air-to-water ratios. Water Research, v. 27, n. 7, p. 1139-1144.

NAZAROFF, W. W.; ALVAREZ-COHEN, L. (2001). Environmental Engineering Science. New York: Wiley. 690 p.

PARK, G.; YU, M.; GO, J.; et al. (2007). Comparison between ozone and ferrate in oxidizing geosmin and 2-MIB in water. Water Science and Technology, v. 55, n. 5, p. 117-125.

REBOUÇAS, A. C.; BRAGA, B.; TUNDISI, J. G. (2006). Águas Doces no Brasil: Capital Ecológico, Uso e Conservação. 3. ed. São Paulo: Escrituras. 748 p.
REISS C.R.; ROBERT, C.; OWEN, C.; et al. (2006). Control of MIB, Geosmin and TON by membrane systems. Journal of Water Supply Research and Technology - AQUA, v. 55, n. 2, p. 95-108.

RICHTER, C.A.; AZEVEDO NETTO, J.M. (1991). Tratamento de Água. Tecnologia Atualizada. São Paulo, Edgard Blücher, 332 p.

SRINIVASAN, R.; SORIAL, G. A. (2011). Treatment of taste and odor causing compounds 2-methyl isoborneol and geosmin in drinking water: a critical review. Journal of Environmental Sciences, v. 23, n.1, p.1-13.

THOMPSON, T.; FAWELL, J.; KUNIKANE, S.; et al. (2007). Chemical Safety of Drinking Water: Assessing Priorities for Risk Management. Geneva: World Health Organization. 160 p.

TUNDISI, J. G.; TUNDISI, T. M. (2008). Limnologia. São Paulo: Oficina de Textos. $630 \mathrm{p}$.

UNITED NATIONS ENVIRONMENT PROGRAMME GLOBAL ENVIRONMENT MONITORING SYSTEM (UNEP GEMS). (2008). Water Quality for Ecosystem and Human Health. $2^{\text {nd }}$ ed. Burlington, Ontario: UNEP GEMS/Water Programme.

WATER ENVIRONMENT FEDERATION (WEF). (2006). Membrane Systems for Wastewater Treatment. Alexandria, VA: WEF. 284 p.

WESTERHOFF, P.; RODRIGUEZ-HERNANDEZ, M.; BAKER, L.; et al. (2005). Seasonal occurrence and degradation of 2-methylisoborneol in water supply reservoirs. Water Research, v. 39, p. 4899-4912.

WORLD HEALTH ORGANIZATION (WHO). Guidelines for Drinking-Water Quality. 3 rd ed. Geneva, 2004. 513 p.

YOUNG, W.F.; HORTH, H.; CRANE, R.; et al. (1996). Taste and odour threshold concentrations of potential potable water contaminants. Water Research, v. 30, n. 2, p. 331-340. 